\title{
UN CASO DE INGENIERÍA HIDRÁULICA PREHISPÁNICA EN LA CUENCA ALTA DEL VALLE DE NEPEÑA, EL SISTEMA DE IRRIGACIÓN HUIRU CATAC
}

\author{
A CASE OF PREHISPANIC HYDRAULIC ENGINEERING \\ IN THE UPPER BASIN OF THE NEPEÑA VALLEY, \\ THE HUIRU CATAC IRRIGATION SYSTEM
}

\author{
Jesús Maza Pomal
}

\section{RESUMEN}

La presente investigación tiene como finalidad, dar a conocer y revelar, desde el punto de vista arqueológico, un ejemplo de ingeniería hidráulica prehispánica reportado para la parte alta del valle de Nepeña. Los datos presentados en este artículo son el resultado de sucesivas exploraciones arqueológicas con el objetivo de documentar las características básicas de este antiguo sistema de irrigación; el cual, vale acotar, no ha recibido la atención científica que merece. Se postularán algunos planteamientos, a partir del contexto arqueológico asociado, para una posible filiación cronológica del canal y los sitios arqueológicos prospectados. El análisis de la evidencia arqueológica asociada y el uso de metodologías GPS permitieron estimar algunos datos preliminares para conocer la naturaleza de esta obra hidráulica prehispánica.

PALABRAS ClAVE: Hidráulica, Cordillera Negra, arqueología, riego prehispánico, valle de Nepeña.

1 Bachiller de la Escuela Académico Profesional de Arqueología de la UNMSM. Ponente en distintos eventos académicos en el ámbito nacional. Cursa estudios de Geomática como segunda carrera profesional.Email: jesusbrave@hotmail.com 


\begin{abstract}
The present investigation has like aim, to present and to reveal, from the archaeological point of view, an example of prehispanic hydraulic engineering reported for the high part of the valley of Nepeña. The data presented in this article are the result of successive archaeological explorations with the aim of documenting the basic characteristics of this ancient channel, which, it is worth mentioning, has not received the scientific attention it deserves. Some approaches will be postulated, from the associated archaeological context, for a possible chronological filiation of the channel and the prospected archaeological sites. The analysis of the associated archaeological evidence and the use of GPS methodologies allowed estimating some preliminary data to know the nature of this prehispanic hydraulic work.
\end{abstract}

KEY WORDS: Hydraulics, Cordillera Negra, archeology, pre-Hispanic irrigation, Nepeña

\title{
INTRODUCCIÓN
}

En las cimas de la Cordillera Negra se origina el ciclo hídrico del valle de Nepeña, el cual depende de la capacidad de retención hídrica que puedan tener las altas cumbres, y de esta manera, mantener llenas las lagunas altoandinas y el acuífero, las cuales afloran valle abajo en manantiales conocidos como puquios.

Pero, también existe y se origina un canal hidráulico antiguo, el cual destaca sobre todo por su considerable longitud. Esta obra prehispánica ha permanecido prácticamente incólume al paso del tiempo y los elementos erosivos. De manera general, el canal Huiru Catac se convierte en el eje principal de un complejo sistema de irrigación prehispánico que nace en las montañas más elevadas de la Cordillera Negra.

La fuente de este canal se encuentra en la laguna de Tocanca, a $4500 \mathrm{msnm}$ aproximadamente y no es más que un ejemplo prodigioso del alto grado de conocimiento que el antiguo peruano logró para superar las adversidades geográficas con el fin acondicionar la naturaleza para su consciente provecho. Dicha obra hidráulica interconectaba un conjunto de lagunas (debidamente embalsadas), recibiendo la dotación de agua de las mismas para luego desprenderse en ramales secundarios para irrigar otros valles interandinos y que dejaron, en consecuencia de su abandono, antiguas terrazas abandonadas ahora convertidos en suelos áridos y sedientos del líquido elemento (Maza 2016, 2017).

\section{ANTECEDENTES}

En la actualidad, la investigación sobre canales y sistemas de irrigación de carácter prehispánico es abundante y variada (Deza 2001,2010; Regal, 2005). No 
pretendemos realizar una reflexión intensiva sobre ello debido a las pocas líneas que disponemos, y también, al enfoque que pretendemos plantear en este trabajo.

Son los pioneros trabajos de Paul Kosok (1965), en la década de 1940, los cuales hacen un llamado a la comunidad arqueológica para que se estudien los antiguos canales y sistemas de irrigación. La posta fue tomada por distintos investigadores en los años sucesivos, especialmente por los integrantes del Programa Riego Antiguo (Deeds, y otros, 1978; Ortloff, Moseley, \& Feldman, 1982; Pozorski \& Pozorski, 1982). Incluso, algunos como Ortloff (1981) y Farrington (1978, 1980a, 1980b), apuntaron a ir más allá y nos dejaron datos estimados sobre los parámetros hidráulicos de los mismos.

Figuran, también, los trabajos sobre canales prehispánicos y sistemas de irrigación en las regiones altoandinas, realizados sobre todo en los Andes Centrales (Perales \& Loayza, 2011) y regiones sureñas (Berrocal, 2014; Pérez \& Salvatierra, 2012; Salvatierra, 2010; Wright, 2008). Son destacables los trabajos de Kendall $(2008,2009)$ en este aspecto. Algunos autores, como Gelles (1986, 2002) y Mitchell $(1976,1981)$, trataron de explorar la continuación de prácticas ancestrales en comunidades actuales relacionadas al manejo del agua en la cultura andina.

Otros han pretendido demostrar o recusar los planteamientos propuestos por Wittfogel (1957), referentes a la irrigación a gran escala y su relación con el desarrollo de sociedades despóticas.

Cronológicamente, el estudio científico más antiguo sobre prácticas ancestrales relacionadas al manejo del agua en el mundo andino se lo atribuimos al insigne Tello (1923), padre de la arqueología peruana.

Partiendo de lo general a lo particular, podemos decir que hemos mostrado la breve y muy básica reseña sobre estudios arqueológicos referida a canales prehispánicos en el territorio nacional.

\section{Antecedentes específicos en la zona de estudio y el canal Huiru Catac}

Los antecedentes arqueológicos en el valle de Nepeña los podemos rastrear desde épocas de Middendorf(1973) y Squier (1974). Estos estudiosos recorrieron el valle de Nepeña, el primero realizó la ruta al Callejon de Huaylas vía Pamparomás, brindando sus impresiones; y el segundo se limitó a describir los sitios arqueológicos del valle medio. 
En el siglo XIX se realizaron los más grandes descubrimientos en el valle de Nepeña gracias a Tello (2005). Es por esa época que se hicieron conocidos los templos de Punkurí y Cerro Blanco.

Los estudios o referencias directas al canal Huiru Catac los encontramos en dos autores: las primeras publicaciones corresponden a Gambini $(1975,1984)$ y la tercera a Villafana (1986). El primer autor, quien es conocido en el valle de Nepeña, especialmente en el distrito de Cáceres del Perú, por su dedicación a la cultura y a la educación, nos otorga las primeras referencias sobre el mismo. En su primera publicación da a conocer, de manera sucinta, este canal, sugiriendo preliminarmente su trazo y recorrido. Creemos conveniente transcribir la primera descripción que hiciera este investigador para darnos una idea de cómo concibió en primera instancia, esta obra hidráulica prehispánica:

"Es casi seguro que los antiguos peruanos de la zona tuvieron la técnica de los Chimús para la construcción de los canales de irrigación, incontables, diseminados en todos los ramales de la cordillera, hoy convertido en terrenos eriazos. El que más llama la atención es el canal que sale de la laguna de Coñocranra, de $40 \mathrm{~km}$. de longitud, hasta Quihuay Punta, salvando sinuosidades de quebradas y bordeando las rugosidades de los cerros. Del canal madre salen tres ramales: el primero, de Ulto Cruz, para irrigar Rayan, Aliso y la parte occidental de este ramal de la cordillera; la de Llamacunca, para irrigar los terrenos de Querocancha, Marco, Azulranra y Lampanín; y la que desvía de Quihuay Punta a la quebrada de Callhuash" (Gambini 1975: 118-120).

En su posterior publicación, nos proporciona más datos y algunos alcances más específicos sobre este canal prehispánico, los cuales transcribiremos a continuación:

"Se inicia en la laguna Tokanka a 4500 metros de altitud, captando en su curso los desaguaderos de las lagunas Kapao o Kuchi Qocha, Verraco Qocha y Qoñoqranra. (...) se profundiza hasta la naciente de la quebrada Tsoku, cruza la loma del Wiru Katac, salvando dos ondulaciones o desniveles de 80 y 104 metros de largo, mediante el sistema de terraplenes escalonados....sigue su curso bordeando la loma de Pukapampa, cruza la pampa del mismo nombre y penetra en la quebrada de Pakékallo hasta la loma de Recuay Posada, naciente en la quebrada de Kolis. Sigue por la loma de Waka Shikanan, cerros Ultu Cruz y Kiway Punta, donde se le calcula una longitud aproximada de 42 km" (Gambini 1984: 110-111).

Es necesario agregar que Gambini lo conoce como "canal de Tocanca" porque halló el origen del mismo en dicha laguna. Este investigador señala, sin presentar argumentación alguna, que la obra hidráulica corresponde a una construc- 
ción del Formativo Superior ${ }^{2}$. En la presente investigación veremos que no existe base científica ni metodológica para sostener esta tesis.

Villafana (1986) es otro acucioso investigador que propone hacer una reflexión sobre la importancia de este notable sistema hidráulico y su posibilidad de rehabilitarlo. Otorga interesantes descripciones y valiosas fotografías del sistema hidráulico. Este autor asegura que los constructores de este sistema hidráulico fueron los incas. Comprobaremos, en el desarrollo de la presente investigación, la poca o nula base científica que existe para sostener ello.

Es necesario mencionar que ya en la década de 1930, en el marco de los trabajos realizados por la Expedición Arqueológica al Marañón en 1937 a cargo del insigne Julio C. Tello (1956: 330), continuando su viaje desde Casma hacia Santa, pudo obtener referencias de un gran acueducto que provenía de las lagunas de la Cordillera Negra. Sin duda, tal referencia se lo atribuimos al canal Huiru Catac.

\section{ÁREA DE ESTUDIO}

La cuenca del río Nepeña se encuentra aproximadamente a 25 kilómetros al sur de la ciudad de Chimbote, dentro de la jurisdicción de la provincia de Santa, en el departamento de Ancash. El río Nepeña nace en las alturas de los cerros Tres Cruces y Tocanca Punta, y las lagunas Tocanca y Capado; inicialmente este río toma el nombre de quebrada Capado, y mantiene esta denominación hasta la localidad de Ticlla a partir del cual toma el nombre de río Ticlla hasta la confluencia con el río Colcap, formando entonces el río Jimbe. La subcuenca o valle del río Jimbe se encuentra en la parte alta del valle de Nepeña y es un afluente de este último (Figura 1).

\section{DESCRIPCIÓN Y CARACTERÍSTICAS DEL SISTEMA HIDRÁULICO HUIRU CATAC}

El canal prehispánico Huiru Catac toma su nombre debido a que las partes más conservadas de la obra se encuentran en una zona dominada por cerros y lomas conjuntamente conocidas como Huiru Catac. Gracias al trabajo de campo se determinó que el canal matriz o principal tiene una longitud de 28 kilómetros aproximadamente (el trazo reconocible) (Figura 2 y 3), pasando por tres de las

2 Ver Gambini (1984), para una revisión más detallada de la periodificación cronológica de este autor. 
Jesús Maza Poma

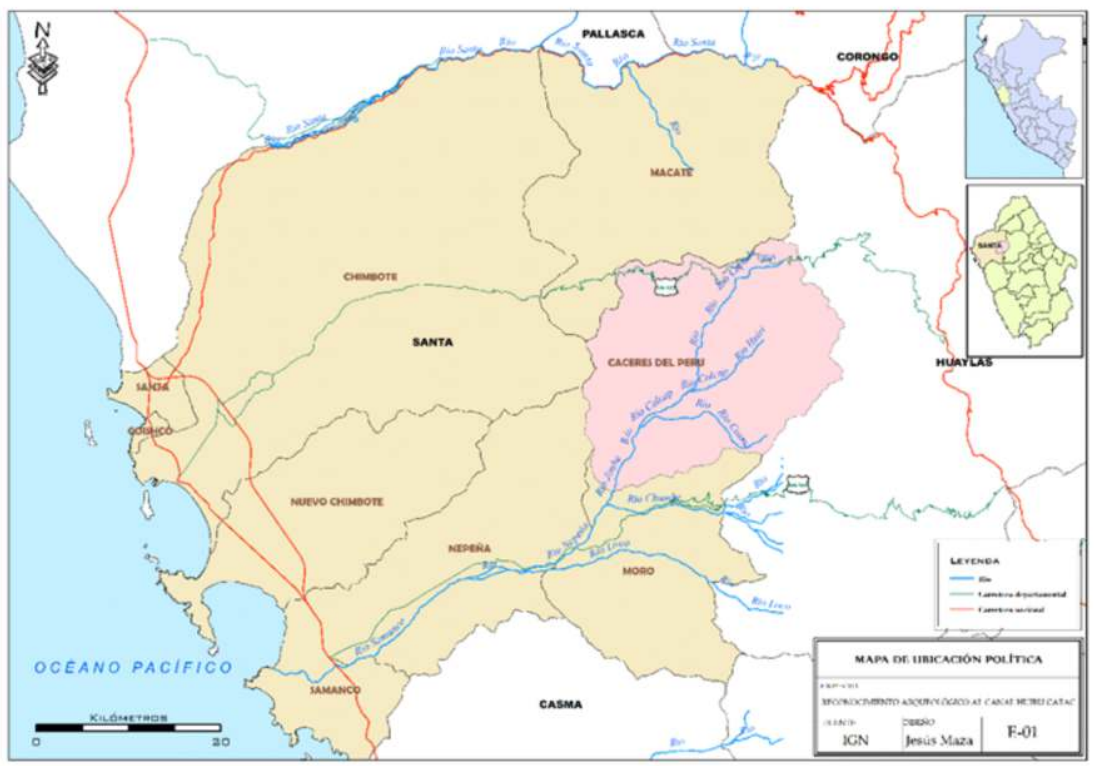

Figura 1. Mapa de ubicación política del área de estudio.



Figura 2. Mapa de ubicación del área de estudio mostrando el canal matriz, los canales secundarios y los sitios arqueológicos identificados. 
ocho regiones naturales descritas por Pulgar Vidal (1998). Nace en la Puna, sigue su recorrido sinuoso por los acantilados de la Suni y desciende hasta los pisos más altos de la Quechua, cerca al pueblo de Quilcay. Los anchos del canal oscilan entre $0,60 \mathrm{~m}$ a $1 \mathrm{~m}$. La pendiente estimada es de 2,42\% para el canal matriz reconocido. Dichos datos fueron procesados haciendo uso de los software SIG (Sistemas de Información Geográfica). Conociendo este dato, se infiere que la preocupación de construir el canal bajo una pendiente moderada, acorde con lo registrado en otros canales matrices prehispánicos (Farrington, 1980a), con el fin de mitigar y minimizar el impacto erosivo del flujo de agua, fue determinante para los constructores. Poco se sabe acerca de los instrumentos utilizados para el cálculo y el diseño en el Antiguo Perú. Sin embargo, la evidencia etnohistórica indica que las sociedades prehispánicas desarrollaron sus propios sistemas de contabilidad y registro, tales como los quipus, yupanas y ábacos (Antúnez de Mayolo S., 1986). Por otro lado, algunos autores han postulado la probabilidad de que se haya utilizada un instrumento similar a una mira que permita realizar cálculos básicos de trigonometría (Ortloff, Feldman, \& Moseley 1985:84).

Se identificaron tres canales secundarios o de derivación. Estos sirvieron para llevar el agua desde el canal madre hasta el lugar de uso. Podían ser utilizados en actividades agrícolas, artesanales y domésticas. Debido a los pocos vestigios que quedan de estos, se reconocieron directa e indirectamente dichos ramales. Directa cuando se pudo identificar y registrar su trazo en el terreno e indirecta mediante teledetección y análisis de imágenes satelitales (SAS PLANET).

El primer canal secundario se origina en el tercer acueducto. Irrigaba el flanco Norte de los cerros Ticas y Ulto Cruz, específicamente las zonas de Tambar, Kachap y Conchas (actual distrito de Macate). Por medio del análisis de imágenes satelitales se evidenció que este ramal (en la imagen satelital el canal se define como un rasgo lineal siguiendo la curva de nivel) pasa cerca de un posible sitio arqueológico (conocido como Tambillo). Realizada la verificación en campo, se identificó este asentamiento prehispánico cuya característica principal reside en su composición arquitectónica y la distribución espacial de sus estructuras. Está compuesto principalmente de dos recintos rectangulares, ambos con divisiones internas, y otras estructuras menores asociadas (especialmente pequeños recintos de forma irregular). Las medidas del primer recinto rectangular, ubicado en el sector oeste del sitio, son de 30 metros de largo por 10 metros de ancho; mientras que el segundo alcanza los 25 de largo por 8 de ancho aproximadamente. A unos 50 metros al noreste del sitio se halló una plataforma artificial, probablemente 
con fines ceremoniales, la cual está orientada a las cimas del Coñocranra, la cual será comentada más adelante.

El segundo canal secundario se desprende de la quebrada Ulto Cruz e irrigaba las zonas altas de Rayan, Querocancha y Azul Ranqra. Fue reconocido directamente en algunos tramos.

El tercer, y último ramal, se origina metros antes de llegar al sitio arqueológico Cerro Kiway, y vertía sus aguas en inmediaciones de la quebrada Qishuar Puquio. Fue reconocido directamente y tiene una longitud de $955 \mathrm{~m}$. Se encuentra colapsado en algunos sectores. Gambini (1984: 111) sostiene que en inmediaciones de Kiway Punta se represaba el canal matriz. En la actualidad, existe cierta depresión natural similar a una zanja que podría representar los vestigios de un antiguo reservorio aunque no se podría descartar su carácter defensivo; ejemplos de estas zanjas los podemos encontrar en el estudio de Bazán (2011) en las quebradas de Santo Toribio y Auquish Uran, a las cuales confiere un carácter defensivo.

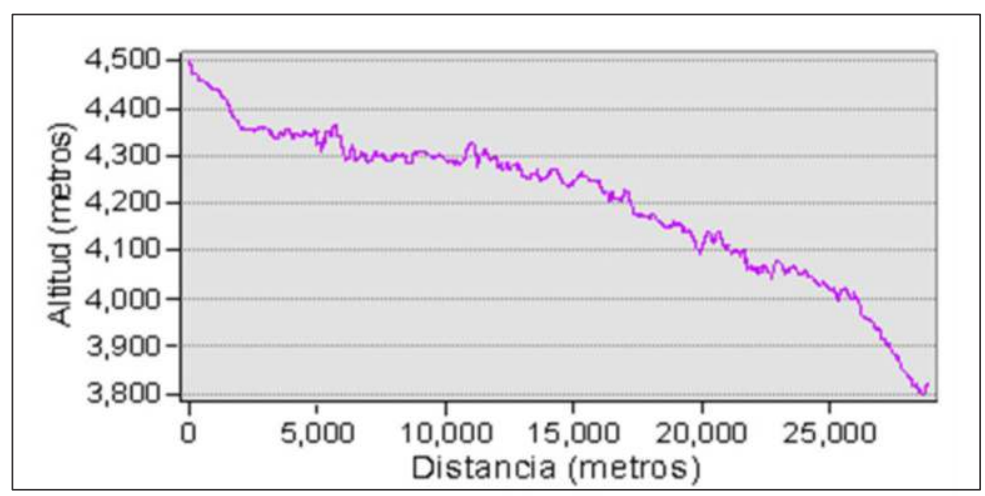

Figura 3. Perfil longitudinal del canal matriz Huiru Catac.

Para una mejor comprensión geográfica del canal matriz se optó por dividirlo en cuatro tramos, los cuales vienen definidos por los accidentes naturales más importantes encontrados en el área, tales como los cerros y las quebradas. (Tabla 1).

Tramo I: El canal nace en la laguna Tocanca, a 4500 msnm (Figura 4). Se hallan muy deteriorados los antiguos muros del dique de contención de esta laguna. Si esos muros son prehispánicos, no podemos asegurarlo con análisis superficiales. Lagunas represadas de este tipo han sido documentadas por Lane (2006a, 
2009, 2014) en la cuenca de Pamparomás y Vivanco (2015) en Arequipa. Es probable que en la construcción del canal se reforzaran los muros de contención de las lagunas con el fin de controlar el flujo de agua hacia el canal. Sus primeros 200 metros los hace en dirección noroeste, luego, al llegar a la quebrada Capado Cocha (donde recibe las aguas de la laguna del mismo nombre), gira en dirección suroeste unos 2 kilómetros. En este punto vuelve a dirigirse hacia el norte, en dirección de la laguna Coñocranra. Luego, después de recibir las aguas de esta laguna, gira en dirección oeste. Sigue en esta dirección 1 kilómetro. A esta altura el trazo del canal es distinguible. Es aquí donde el canal pasa por una serie de acantilados, en donde los constructores no pudieron horadar la roca y levantaron inmensos muros de contención o sostenimiento de hasta 8 metros de altura. La mampostería de estos muros está compuesta de rocas sin labrar o labradas rústicamente. A este sector se le ha denominado primer acueducto.

Tramo II: Al llegar a la quebrada San Mateo, vuelve a tomar el rumbo oeste por unos 2 kilómetros, no sin antes pasar por una serie de pequeños muros o terraplenes construidos para salvar los desniveles del relieve, los cuales se encuentran en su mayoría colapsados. Se distinguen las piedras en la parte inferior del cimiento de los muros producto del colapso de estas estructuras. Aquí se presentan majestuosamente las obras de mayor envergadura, los denominados acueductos, el segundo (Figura 5) y el tercero respectivamente.

Tabla 1

TRAMOS DEL CANAL MATRIZ DEL SISTEMA HUIRU CATAC.

\begin{tabular}{|c|c|c|l|}
\hline \multicolumn{4}{|c|}{ Cuadro Técnico del canal matriz Huiru Catac } \\
\hline Tramo & Inicial & Final & \multicolumn{1}{c|}{ Descripción } \\
\hline I & Km 0 + 000 & Km 5 + 730 & $\begin{array}{l}\text { desde su nacimiento hasta la quebrada } \\
\text { San Mateo. }\end{array}$ \\
\hline II & $\mathrm{Km} \mathrm{5+730}$ & $\mathrm{Km} 15+140$ & $\begin{array}{l}\text { desde la quebrada San Mateo hasta la } \\
\text { loma de Recuay Posada. }\end{array}$ \\
\hline III & $\mathrm{Km} 15+140$ & $\mathrm{Km} \mathrm{25+841}$ & $\begin{array}{l}\text { desde la loma de Recuay Posada hasta } \\
\text { el cruce de Ventanilla. }\end{array}$ \\
\hline IV & $\mathrm{Km} \mathrm{25+841}$ & $\mathrm{Km} \mathrm{28}+830$ & $\begin{array}{l}\text { desde el cruce de Ventanilla hasta el } \\
\text { fin del trazo reconocible en las } \\
\text { inmediaciones de Cerro Kiway. }\end{array}$ \\
\hline
\end{tabular}


Jesús Maza Poma

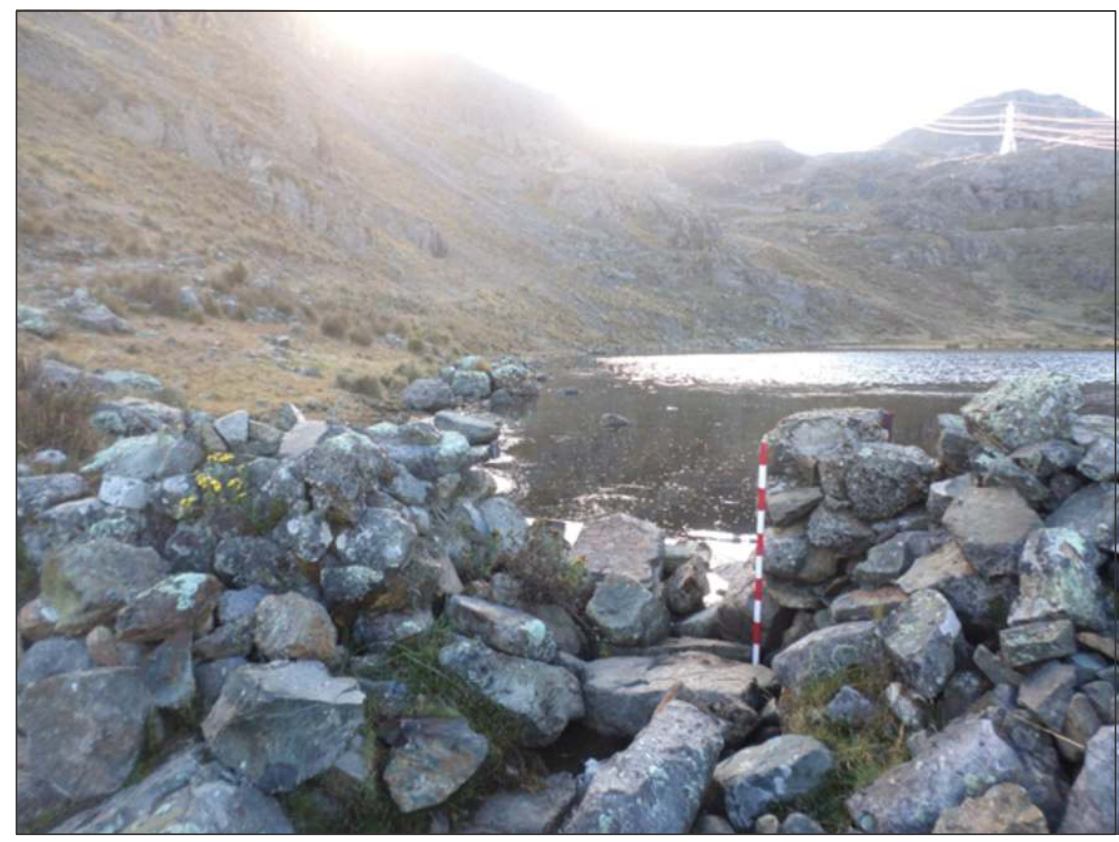

Figura 4. Bocatoma actual de la laguna Tocanca.

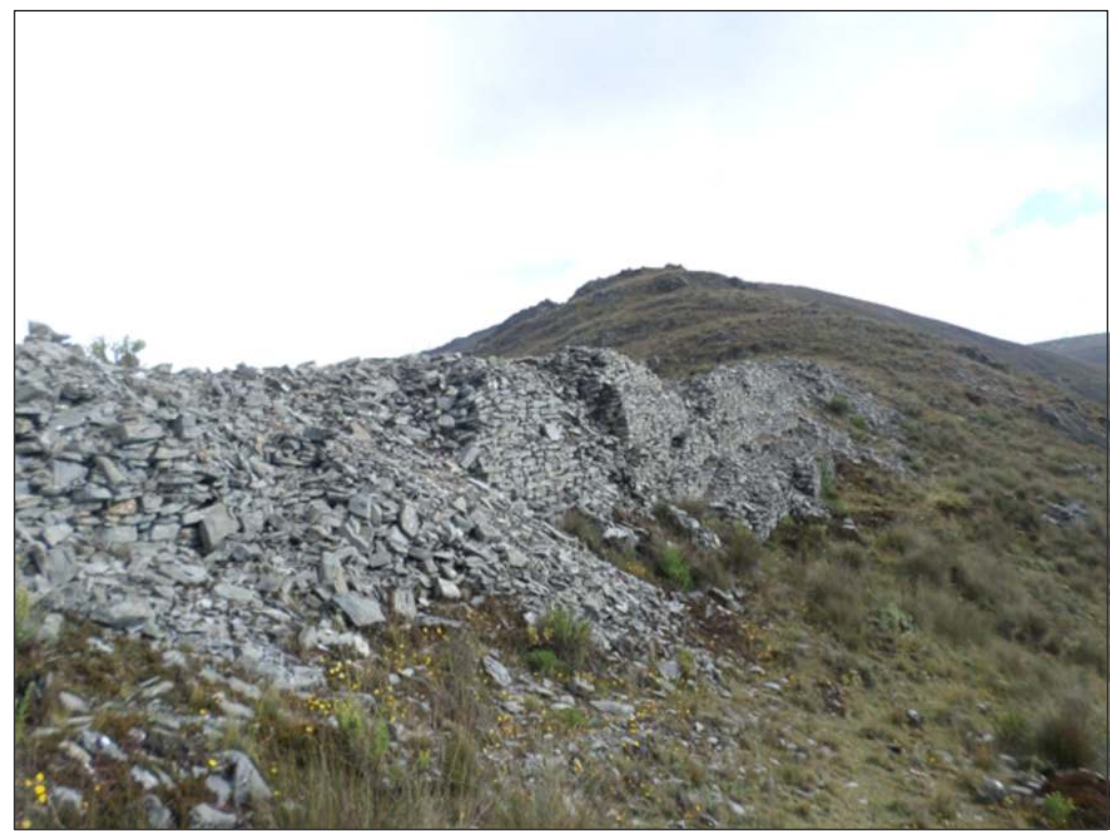

Figura 5. Panorámica del segundo acueducto. Vista Norte-Sur. 
La monumentalidad de estas construcciones, el diseño y su buen estado de conservación, representan la evidencia para inferir el alto grado de conocimiento en ingeniería hidráulica y la existencia de especialistas en el diseño, así como de las probables ceremonias y actividades sociales vinculadas a la construcción de tales obras. Asociado y a pocos metros de los acueductos se hallan vestigios de recintos semicirculares y rectangulares que probablemente sean espacios públicos utilizados para actividades relacionadas a la construcción de los monumentales acueductos.

El canal matriz sigue su curso en dirección sur, bordeando una nueva loma (Pukapampa o Recuay Posada i?); al trasponer esta loma ya no es distinguible, por lo que se estima su recorrido, considerando la pendiente que pudiera haber seguido el canal. Al llegar al extremo de la loma, en la zona limítrofe de Macate y Jimbe, se encuentra el primer asentamiento arqueológico no reportado antes y que llamaremos Pukapampa.

Tramo III: Trasponiendo otra nueva loma, la de Recuay Posada o Lacato i? entramos a una zona dominada por los cerros Ticas y Ulto Cruz en la parte superior. De por sí, este lugar da la impresión de esconder muchos sitios arqueológicos; la geografía y las vertientes de agua que bajan por doquier dotan a esta zona con un potencial para futuras prospecciones arqueológicas intensivas. Por esta zona son muy frecuentes las cuchillas de agua que bajan de la cima de los cerros así como los ojos de agua o puquios ubicados muy cerca y en la parte superior del canal. Es probable que estas fuentes naturales de agua hayan alimentado el canal, indicando así un aprovechamiento máximo del recurso hídrico. Debemos anotar que los pobladores de la zona refieren la existencia de pequeños canales que se originan en una laguna situada en la parte superior de este sector, conocida como Cushuro, que, según fotografías observadas, muestra evidencias de haber sido embalsadas pretéritamente.

Antes de llegar a la cima de Kiway Punta se encuentra el asentamiento arqueológico denominado Cerro Kiway, el cual se ha dividido en dos sectores.

Tramo IV: Después de Kiway Punta, se pudo divisar el trazo del canal y se pudo retomar su recorrido unos metros más abajo. Siguiendo el trazo del canal, no tardamos en recorrer un kilómetro y se llega al punto donde supuestamente termina el canal Huiru Catac, al menos el trazo más definido. Es curioso que el trazo del canal se pierda en un lugar donde podría haber seguido tanto para el valle de Lacramarca como para el valle de Nepeña. Gambini (1984) menciona que el 
canal seguía su trazo hasta la costa, en las inmediaciones de la hacienda Tambo Real y que flanqueaba la parte Norte del cerro Corona. Creemos que la vegetación y el paso del tiempo han borrado el trazo del canal. Es necesario anotar que el canal es utilizado en la actualidad, a partir de Kiway Punta, como un sendero transitable para personas y animales. Este tipo de posterior uso ha sido reportado para canales abandonados en otras regiones del país (Gelles, 1986; Regal, 2005).

\section{RIEGO, AGUA Y SIMBOLISMO EN LOS ANDES}

Sobre el riego y la agricultura andina consideremos oportunamente la opinión de Eduardo Grillo:

"Considérese debidamente al respecto que el Perú es uno de los pocos centros de creación de la agricultura y también de invención del riego en la historia de la humanidad y que sus aportes en este ámbito del quehacer humano son, por lo tanto, no sólo notables, sino también sui generis" (Grillo 1988: 17-18).

El agua en la cosmovisión andina es considerada como el elemento vital para originar la vida en los Andes, la intensa relación de los pueblos andinos con el líquido vital, ha originado diversas e importantes expresiones e interpretaciones culturales, que determinan las formas de su manejo (Gerbrandy \& Hoogendam, 1998; Grillo, 1988).

Rebeca Carrión (2005 [1955]) señala la importancia del culto al agua en los antiguos peruanos y nos muestra, las diferentes manifestaciones materiales con que se concibió ello, especialmente en las vasijas conocidas como paccha. Constata la existencia de mitos y leyendas asociadas a la construcción de grandes obras prehispánicas y la relación que éstas tienen con el carácter productivo de las sociedades del Antiguo Perú.

Sherbondy (1987) analiza la importancia que tuvo el agua en tiempos incaicos y la organización hidráulica en el Cusco, afirmando que ello fue emulado en las provincias más importantes del Tahuantinsuyo. La investigación realizada por Gelles (2002) y Valderrama (1988) en el valle del Colca confirma dicho planteamiento, y de esta manera se han hallado rezagos de la organización hidráulica en distintos lugares en los Andes.

Farfán (2002) y Carlier (2008) describen las prácticas ancestrales que aún sobreviven en las comunidades de la cuenca alta del valle de Chillón, las cuales, afirman los investigadores, conforman la continuación de ritos prehispánicos. Examinan la estrecha relación que existe entre los lagos y la mama qocha (mar), 
aspecto analizado también por Sherbondy (1982) y Antúnez de Mayolo (1986), agregando la asociación de los lagos con las llamas y diversos cultos locales en los Andes. La investigadora Sherbondy refiere sobre la existencia del concepto andino que explica el origen de los pueblos en las pacarinas o upaimarcas (Glowacki \& Malpass, 2003). Explica que los antepasados viajaron por rutas acuáticas subterráneas para formar los ayllus de los Andes.

En la presente zona de estudio, uno de los objetivos fue identificar algunos rasgos asociados del paisaje que podrían indicarnos acerca de los ritos o ceremonias realizadas que se puedan encontrar relacionadas al sistema hidráulico. Más allá de los picos y cerros prominentes como el Coñocranra o el Tocanca, debería haber existido algún lugar en el terreno donde venerar y/o realizar actividades relacionados al culto a las montañas o al agua, considerando la dimensión e importancia que alcanzó este complejo sistema de regadío.

Una inspección al primer canal secundario que, como dijimos, se desprende del tercer acueducto con dirección a Kachap y Tambar, permitió identificar un sitio denominado Tambillo, en el cual se encontró una plataforma de probable función ceremonial. Su orientación y disposición en el paisaje sugiere ello (Figura 6). Revisando las publicaciones de Cavero (2010), sobre los ushnus y santuarios de altura en la zona de Ayacucho, existe cierta similitud entre estas evidencias arquitectónicas. Debemos señalar que la mencionada plataforma tiene una escalinata para acceder a su parte superior y en la parte central de esta se halló un pozo cuadrangular excavado en la tierra, el cual podría corresponder a la zona de ofrendas o en todo caso a la evidencia de un huaqueo. Las estructuras asociadas a esta plataforma se componen principalmente de dos recintos rectangulares de considerable longitud ya comentados previamente. Inicialmente, mediante el análisis de las imágenes satelitales previo a la inspección del sitio, se consideró tentativamente que dichas estructuras podrían corresponder a unas estructuras tipológicamente conocidas como kallankas, que, como se sabe, corresponden a estructuras de filiación incaica. Los recintos que identificamos tienen divisiones internas, por lo tanto, partiendo de la definición otorgada por Hyslop (2016), no podrían corresponder a las denominadas kallankas. Asimismo, no se identificó material cerámico en superficie que podría sugerir la función del sitio. La poca altura de los muros que componen los recintos rectangulares podría sugerir que la parte superior estuvo conformado de un material no detectable arqueológicamente (adobe), como ya lo señaló Lane (2006a: 106) para la zona de Pamparomás. Es necesario recalcar que, según la historiografía tradicional, el otrora pue- 
blo de Tocas fue el lugar de nacimiento de Contarhuacho, mujer secundaria de Huayna Capac e hija del curaca y líder étnico de los Ananhuaylas (Zuloaga, 2012). El canal secundario se dirige justamente en última instancia hacia Tocas, por lo tanto, resulta prioritario conocer la naturaleza de este ramal para evaluar las zonas productivas y la relación probable con el pueblo de Tocas. Ya en su momento, Varón (1993) insinuó que debería explorarse arqueológicamente esta zona considerando lo anteriormente expuesto para dilucidar la naturaleza de la ocupación inca en esta región. Por ahora, solo nos limitaremos a presentar las evidencias debido a que se está preparando otro escrito sobre los asentamientos prehispánicos del valle de Jimbe en el que se discutirán con más datos la naturaleza de los asentamientos arqueológicos identificados.

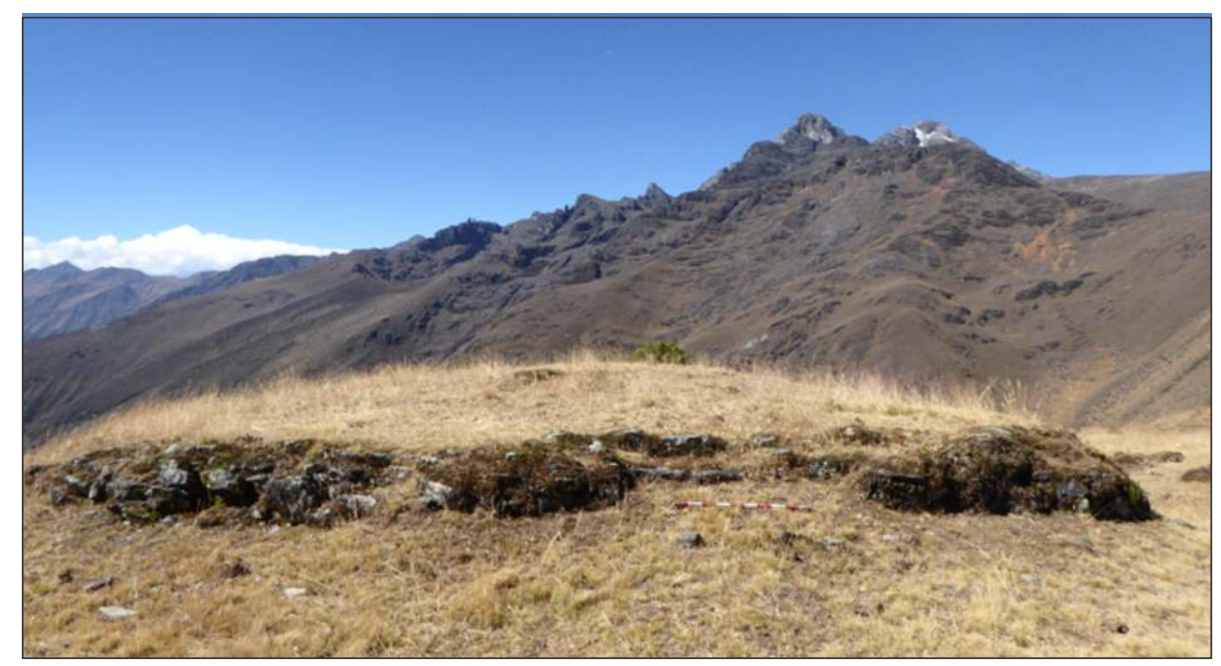

Figura 6. Plataforma ceremonial identificada en Tambillo. Nótese la orientación con respecto al cerro Coñocranra. Vista Oeste-Este.

\section{TECNOLOGÍA CONSTRUCTIVA}

El sistema hidráulico Huiru Catac se compone de conductos artificiales abiertos no revestidos y fue construido, en sus diferentes tramos, de acuerdo a las condiciones geográficas y el relieve por donde se diseñó su trazo, empleando los materiales cercanos del área. Aunque Villafana (1986: 51) había señalado la probable presencia de túneles, la investigación realizada no ha confirmado tal supuesto. Por el contrario, proponemos, a partir del reconocimiento realiza- 
do, la inexistencia de tales rasgos debido a que no se encontraron indicios de los mismos.

La tecnología constructiva identificada, preliminarmente, se agrupa en cuatro tipos. En los primeros kilómetros, bastó con realizar aplanamientos y nivelación del terreno (caso 1) (Figura 7). En otros casos, se tuvo que erigir pequeños muros de contención de un metro promedio aproximadamente. Estos muros fueron levantados con rocas rústicas de cerro y, al parecer, tuvo una delgada capa de mortero, no muy distinguible en la actualidad (caso 2) (Figura 8). Asimismo, en determinados casos se tuvo que horadar la roca (caso 3) (Figura 9) para darle paso al trazo del canal. Sobre la manera como realizaron estos trabajos en la roca, las fuentes etnohistóricas (Garcilaso, 1959) mencionan la presencia de algunas



Figura 7. Técnica constructiva correspondiente al caso 1. 
Jesús Maza Poma

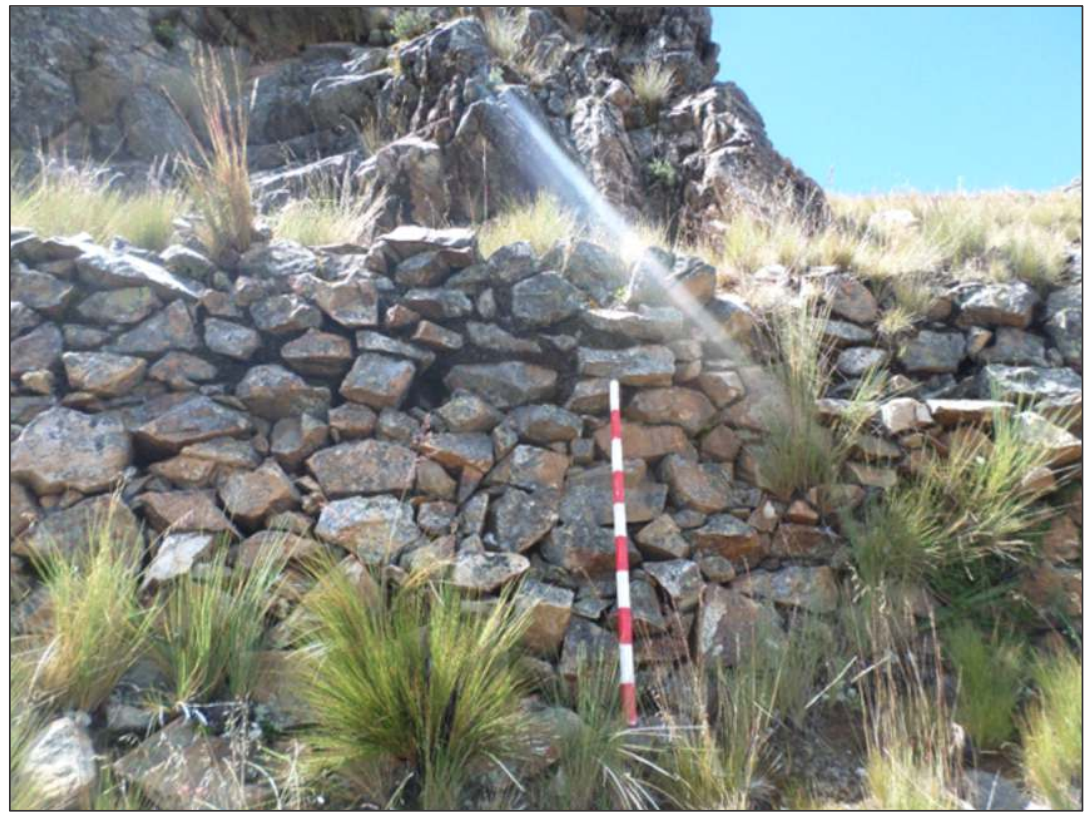

Figura 8. Técnica constructiva correspondiente al caso 2.



Figura 9. Técnica constructiva correspondiente al caso 3. 


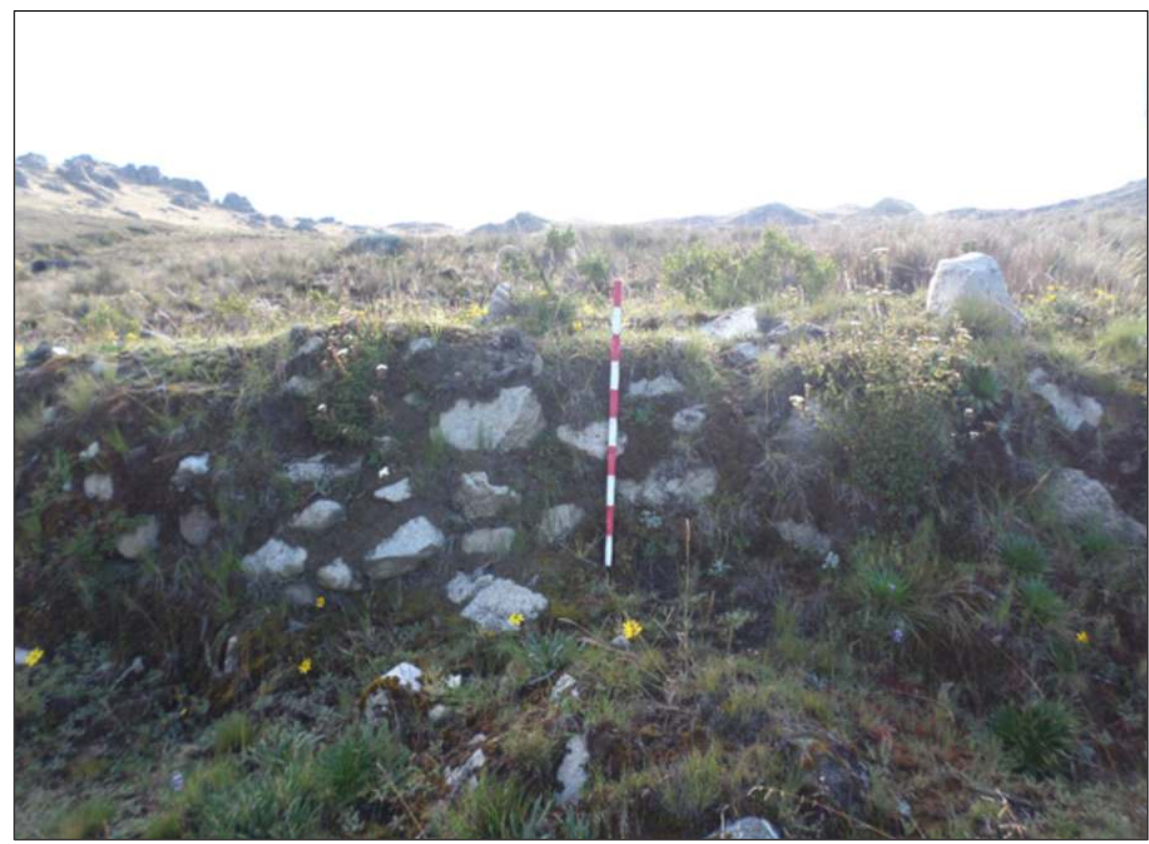

Figura 10 Técnica constructiva correspondiente al caso 4.

piedras especiales para tal tarea, como la higuana y el champi. En última instancia, en suelos donde existía una cobertura general más amplia se identificó, en la construcción interna del canal, la colocación de "champas" a modo de relleno constructivo (caso 4) (Figura 10), técnica que aún sigue en funcionamiento en los Andes (Van der Zel 1989: 49).

Siguiendo con el análisis de la tecnología constructiva del canal matriz, se identificaron hasta tres acueductos, los cuales destacan por su monumentalidad. En la edificación del primer acueducto, encontramos rocas sumamente rústicas sin labrar o labradas toscamente, superpuestas y unidas con una argamasa simple o a veces en seco. Los acueductos siempre fueron construidos con una finalidad: la de darle una pendiente continua y adecuada de caída al flujo de agua. De esta manera se evitarían los saltos hidráulicos que provocarían la erosión acumulativa del canal en las paredes laterales o en el piso del mismo, aspectos que perjudicarían el funcionamiento de la obra (Farrington, 1980a), y que permite inferir el grado de conocimiento en ingeniería de los constructores. Los dos acueductos siguientes fueron construidos utilizando como principal material constructivo la 
piedra caliza, y al parecer, en el mismo momento, interpretación sugerida por estar ambos construidos del mismo material y técnica constructiva.

En el relleno interno de los terraplenes, destacan las rocas calizas de regular tamaño en el centro, así como las rocas planas de menor tamaño en las caras expuestas del canal. En su parte interior, el canal parece haber tenido una capa de argamasa más compacta. El tipo de roca utilizado para erigir los acueductos, como ya se comentó, fue la caliza. Sin embargo, tenemos conocimiento por referencias bibliográficas (Villafana, 1986), el uso de la piedra pizarra en su constitución. Para determinar ello, se recogieron muestras de distintos tipos de rocas en base a sus características físicas y se llevó a cabo un pequeño experimento para conocer si reaccionaban con el vinagre como lo hacen las calizas. El resultado fue que, aquellas aparentes piedras pizarras, también reaccionaron con efervescencia como las anteriores y por lo tanto, se descarta su presencia.

\section{CRONOLOGÍA, DATOS PALEOAMBIENTALES Y RELACIÓN CON LOS SITIOS ARQUEOLÓGICOS IDENTIFICADOS}

Para plantear una cronología tentativa, de carácter relativo, es necesario y conveniente analizar profundamente la tecnología constructiva, la cual nos podría aportar algunos datos para estudiarlos comparativamente con otros casos reportados. Los datos paleoambientales servirán para dilucidar el posible contexto climático que propició la construcción de una obra de esta magnitud. Es probable que las irregularidades en las precipitaciones y la concurrencia de fenómenos del Niño, plantearan medidas de seguridad productiva y alimentaria (Contreras, 2010; Kendall \& Rodriguez, 2009; Ortloff \& Moseley, 2009). Y por último, la relación con los sitios arqueológicos y el contexto arqueológico asociado, permitirán, tal vez, obtener algunas aproximaciones para entender y explicar la naturaleza de este sistema hidráulico.

Las características constructivas del canal no respaldan su filiación cronológica con los incas. Los parámetros incaicos, en su mayoría, se caracterizan por estar asociados al uso intensivo del labrado de la piedra (Kendall \& Rodríguez, 2009; Regal, 2005; Wright, 2008) y la presencia de poblaciones destinadas para tales trabajos, conocidos como mitimaes o mitmas (Valdez \& Valdez, 1998). Estos eran desplazados desde diversas zonas de los andes para realizar estas construcciones públicas en favor del estado incaico. Herrera (2005) reporta la existencia de una probable población mitma en Huampo, sitio ubicado en la cuenca alta del 
valle de Casma, y paso natural entre ese valle y el de Nepeña, mediante la subcuenca del río Loco. La distancia entre el sistema Huiru Catac y esta probable población mitma es muy grande ( $40 \mathrm{~km}$ en promedio) para creer que ellos pudieron construir tal obra, por lo tanto, se puede descartar esta idea. Deberíamos agregar que se ha discutido anteriormente la naturaleza de la ocupación inca en la zona, no pudiendo hasta ahora dilucidarse de una manera clara (Aspillaga, 1953; Lane, 2011; Proulx, 1973, 2007).

Una mirada a los datos paleoambientales que se tienen en la actualidad, gracias a investigadores interesados en el paisaje arqueológico y su relación con el desenvolvimiento de las sociedades prehispánicas, permiten conocer el contexto paleoecológico de la zona de estudio. En la reciente tesis de Silva (2016), se compilan estos estudios para relacionarlos al cambio de tecnologías líticas en la zona del nevado Huandoy. Debido a la cercanía de ese estudio con nuestra zona de investigación, podemos hacer comparaciones aceptables. Dicho estudio muestra un período de sequía progresiva a partir del Horizonte Medio (650-1000 d.C.) llegando a puntos máximos en el Intermedio Tardío (1000-1460 d.C.). Los análisis realizados a los núcleos de hielo del Huascarán revelan un periodo de sequía comenzando alrededor de 1100 d.C. Estos datos se evidencian en la considerable cantidad de polvo asociado a temperaturas elevadas (Ortloff \& Moseley, 2009; Thompson, Mosley-Thompson, Bolzan, \& Koci, 1985).

De igual manera, las investigaciones realizadas por Lane (2006a, 2014, 2016) muestran claramente una progresiva ocupación del valle contiguo de Pamparomás a partir del Horizonte Medio, reflejado en el mayor número de asentamientos prehispánicos asociados a su vez, a sistemas hidráulicos y agropastoriles. Es necesario resaltar la gran documentación de represas de limo que realizó este investigador.

Según los estudios realizados hasta la fecha en la cuenca baja de Nepeña, se identifica la construcción de canales prehispánicos a partir del Horizonte Medio. La causa de tales obras está relacionada a una explosión demográfica que sufrió el valle a partir del Horizonte Medio (Proulx 1973: 97-100, 2007) y es pertinente pensar un contexto parecido para el valle alto. Asimismo, se incrementan las áreas agrícolas y surgen las áreas habitacionales densamente pobladas caracterizadas por un trazo ortogonal. Cabe agregar que la mayoría de canales se sitúan en la margen derecha del río Nepeña. Se tienen reportes de canales en Jimbe (Proulx 2007: 165), Captuy (Gambini 1984:117) y Máquina Vieja. La longitud de estos canales no supera los $5 \mathrm{~km}$. Al parecer, la preferencia por construir canales de 
irrigación en la margen derecha del valle, indicaría un origen norteño para la construcción de tales obras. Como vemos, los datos reseñados indicarían el origen preincaico de esta obra hidráulica.

Hasta aquí, hemos reseñado sobre el contexto arqueológico y paleoambiental de la zona de estudio. Examinemos, ahora, los sitios arqueológicos identificados ubicados en el trazo inmediato del canal para analizar su posible relación con el canal matriz del sistema Huiru Catac. El primer asentamiento, denominado Pukapampa, respetando la toponimia local, está ubicado en una pequeña planicie, asentada en el divortium aquarum de los valles de Jimbe y Macate. Se compone de seis recintos (los que se pudieron identificar) ortogonales asociados a un patio o plaza amplia ubicada en el extremo oeste del sitio. El asentamiento arqueológico se encuentra ubicado en la margen derecha de la carretera en dirección a Huaylas. Con respecto al sistema hidráulico, se ubica en su margen derecha a una distancia de 250 metros aproximadamente, en el tramo II. La arquitectura de este sitio está compuesta, básicamente, por muros y recintos de piedra, los cuales, se edificaron con piedras rústicas y sin labrar; y la altura de los muros preservados no supera los $50 \mathrm{~cm}$. No presenta una conexión evidente con el canal, aparte de estar ubicado cerca del mismo. No se encontraron materiales diagnósticos en superficie, por lo que su filiación cronológica es difícil de determinar. Sin embargo, debido a su ubicación en una zona de puna, indicaría estar relacionado a actividades agropastoriles. Parece ser tardío e inclusive se encontraron restos de actividad cultural moderna.

Un segundo sitio relacionado al sistema por su proximidad y además, por estar asociado aparentemente mediante un camino ${ }^{3}$, es Tzaqanan. Este importante sitio parece que podría dar una explicación sobre quiénes y en qué momento construyeron esta obra hidráulica. Ubicado a $1 \mathrm{~km}$ al sur del canal, a la altura del tramo III, este complejo asentamiento parece ser una aldea prehispánica abandonada intempestivamente en los Andes. El sitio está compuesto de áreas habitacionales, ceremoniales, funerarias y una considerable cantidad de terrazas (Maza, 2017). Este asentamiento se convierte, pues, en un sitio fundamental para entender la dinámica de las sociedades prehispánicas del valle alto de

3 Camino que actualmente es utilizado por los pobladores de Racuaybamba para viajar a Huaylas y Macate. Los pobladores refieren que los orígenes de esta vía se pierden en la memoria de sus ancestros, no pudiendo asegurar quienes fueron los constructores. 
Nepeña. Aproximadamente ocupa un área de 20 hectáreas, y representa por lo tanto, el sitio más grande identificado en asociación directa con la obra hidráulica. Sobre la filiación cronológica se pudo identificar materiales diagnósticos en superficie que permiten asociarlo claramente al Intermedio Temprano (Maza, 2018) (estos hallazgos se componen de fragmentos de caolinita de probable filiación Recuay), pudiendo tener una ocupación anterior según Gambini (1984: 116), con superposiciones culturales probablemente hasta inicios del Intermedio Tardío. La presencia de estructuras funerarias conocidas como chullpas (Figura 11) y variaciones locales de estilos regionales ya conocidos permiten realizar tal inferencia. Se evidencia, también, la presencia de fragmentos de piruros y desechos líticos en superficie de aparentes piedras pizarras.

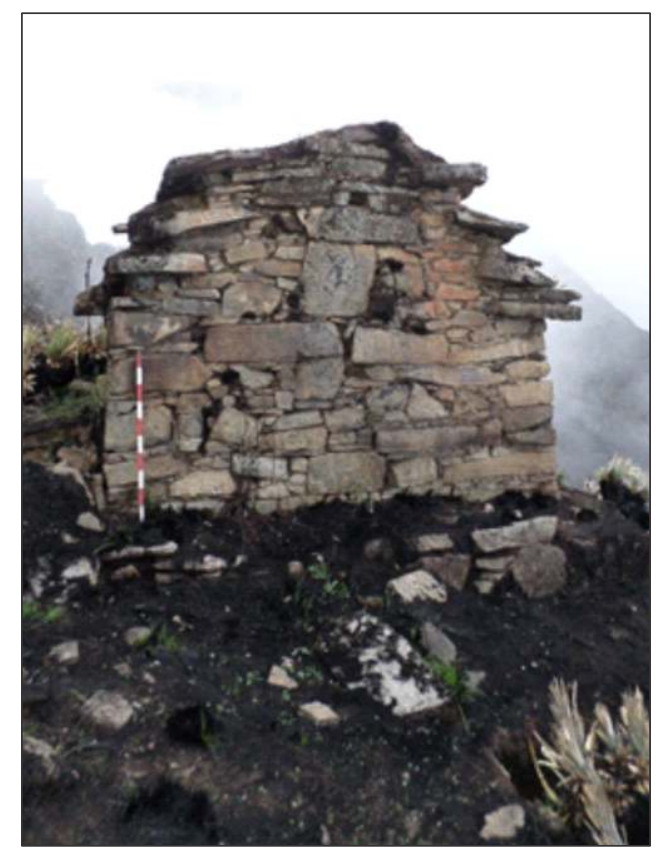

Figura 11. Estructura funeraria tipo chullpa identificada en Tzaqanan.

La asociación de este asentamiento con el canal matriz Huiru Catac es evidente debido a la presencia de un camino prehispánico que une la parte más alta de Tzaqanan (próximo a un sector ceremonial de este sitio evidenciado por la presencia de una llamada caja o tina de piedras labradas) con el canal en un paraje 
cercano a Pukapampa. Asimismo, se hallaron similares patrones constructivos en los muros de las construcciones, especialmente las que corresponden a las terrazas agrícolas. Si se asume que las mismas fuerzas productivas construyeron el canal y este conjunto extenso de terrazas, resulta pues, evidente la clara asociación en técnicas constructivas.

El último sitio asociado al trazo del canal Huiru Catac lo denominaremos Cerro Kiway (Figura 12). Ubicado al final del trazo reconocible del canal y en su margen derecha, este asentamiento está dividido en dos sectores diferenciados a una distancia de 200 metros entre ellos. El sector A se ubica en un montículo natural de diez metros de altura modificado en su parte superior por la arquitectura existente, la cual consiste en una plataforma ortogonal delimitada por muros a modo de recintos y accesos.

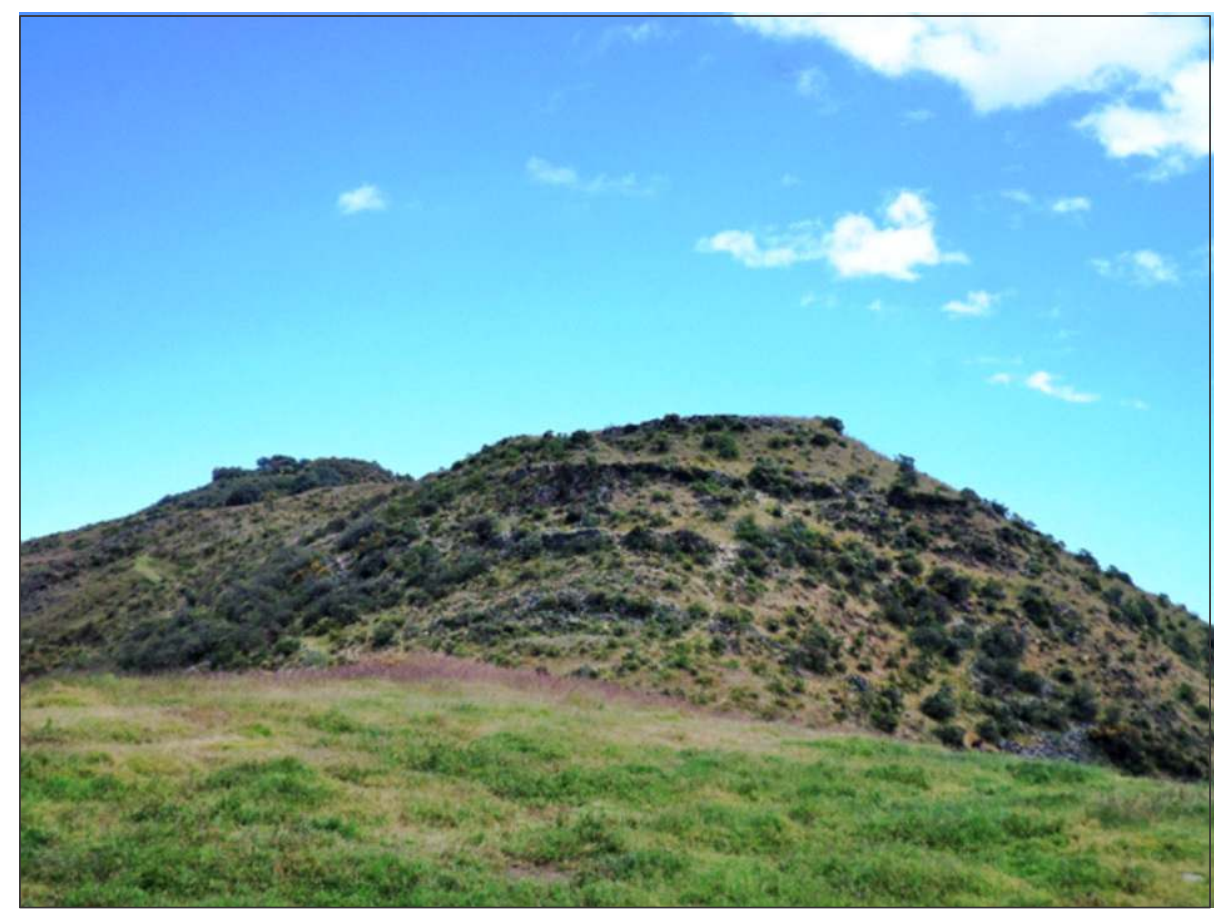

Figura 12. Panorámica del sector superior o sector B de Cerro Kiway. Nótese los muros perimétricos siguiendo la curva de nivel del montículo natural. Vista E-O. 
El sector B se ubica a 200 metros al oeste del sector A y está asentado sobre un gran promontorio, orientado de este a oeste. Este sector se desarrolla en forma alargada siguiendo la cresta del cerro y está delimitado hacia el este por cuatro muros perimétricos sucesivos. Hacia el lado Norte existen vestigios también de muros perimétricos. La arquitectura parecería ser un poco más tardía. Similares patrones arquitectónicos se han identificado en la zona de Auquish Urán y Santo Toribio (Bazán, 2011) afiliados temporalmente al Intermedio Tardío. La cerámica hallada en superficie corresponden a tiestos de pasta gruesa naranja, piruros y como elemento diagnóstico, se registró un fragmento de cerámica similar al estilo Casma inciso (Figura 13) (círculo y punto), correspondiente al Intermedio Tardío según comparaciones con investigaciones regionales de este estilo (Bastiand, 2006; Dagget, 1983); y también hallado en las ocupaciones tardías de Cosma (Navarro 2015, 2016).

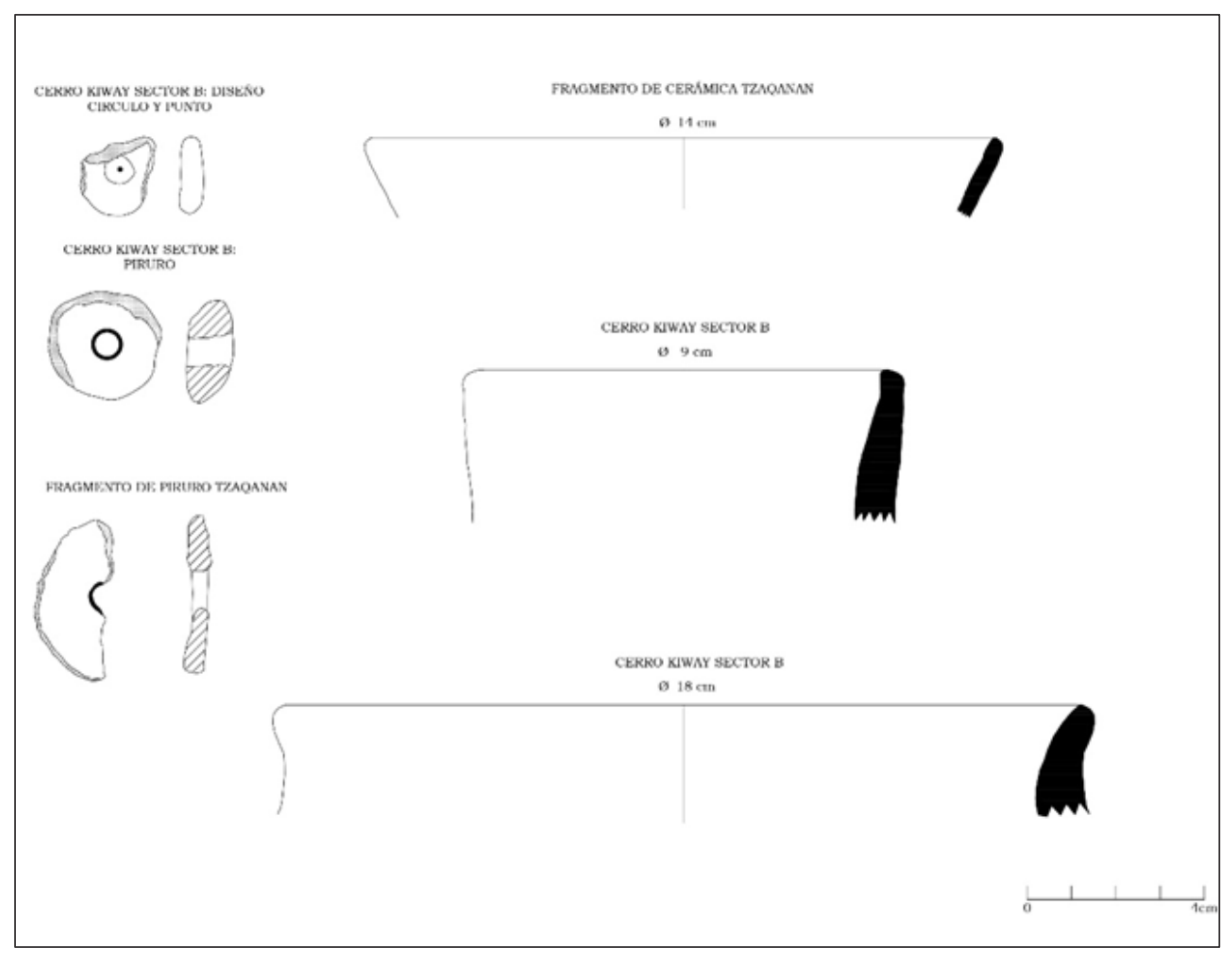

Figura 13. Cerámica registrada en la presente investigación proveniente de Cerro Kiway y Tzaqanan. 
Parece pues, considerando los datos expuestos, ubicar cronológicamente la construcción de esta obra hidráulica en las postrimerías del Horizonte Medio o en el transcurso del Intermedio Tardío. Esta investigación ha permitido demostrar que la construcción del canal no se puede atribuir a los incas. Asimismo, Gridilla (1937) señala en su obra las descripciones de los primeros cronistas que llegaron al valle de Santa y refiere que los españoles encontraron en estado de abandono los grandes canales. Y para apoyar esta hipótesis, al considerar datos etnográficos, vemos que la tradición oral sobre el canal se ha perdido. Valcárcel (1964) sugiere que la tradición oral para los sucesos tiene un límite que no supera los 500 años. Los caseríos y comunidades actuales situados cerca de la obra hidráulica no conocen ni refieren algún mito o leyenda referente a su construcción. Algunos designan genéricamente a los incas la construcción del canal, pero no explican de qué manera y cómo, tal como sí sucede en algunos casos reportados de canales en los Andes (Sherbondy, 1982; Oré, 2005).

\section{MANEJO HÍDRICO INTERCUENCAS}

Un concepto poco desarrollado, y poco explorado por los arqueólogos que estudian sistemas hidráulicos prehispánicos, es el referido al manejo de cuencas hidrográficas que practicaron las sociedades prehispánicas. En la costa norte son conocidas las investigaciones sobre el gran complejo Lambayeque (Deza, 2010; Téllez \& Hayashida, 2004), y un poco más al sur el sistema Moche Chicama materializados por el canal La Cumbre (Ortloff, 1981; Ortloff, Moseley, \& Feldman, 1982). En la costa central tenemos otro caso reportado por Regal (2005) para los valles de Chillón, Rímac y Lurín.

Sin embargo, el estudio de sistemas hidráulicos en las tierras altascon capacidad para administrar el recurso hídrico en más de una cuenca no ha sido desarrollado en su plenitud. Y si lo ha sido, es evidente que es poco tomado en cuenta considerando su naturaleza y envergadura.

El manejo hídrico a nivel intercuencas lleva, de por sí, connotaciones de carácter integrador, debido a la existencia de acuerdos políticos y/o comunitarios por parte de poblaciones benefactoras por excelencia. Conforman evidencias indisolubles que existió, en algún momento aún no determinado precisamente, la conciliación de fuerzas productivas en los tres valles donde dotó de agua el sistema hidráulico. Estos valles son el de Jimbe, Lacramarca y el de Macate. 
Al respecto, Greslou (1988) sostiene que la gestión y manejo de cuencas estaba totalmente integrada a la gestión social, económica y cultural para garantizar la construcción y el mantenimiento de la obra optimizando un racional manejo del conjunto de los recursos y sus posibles influencias en el líquido vital.

\section{CONCLUSIONES}

1. El presente caso de ingeniería hidráulica permite conocer e inferir el alto grado de conocimiento en ingeniería hidráulica que tuvo el antiguo peruano con el fin de aumentar su capacidad productiva. Asimismo, la conservación de algunos valiosos e intactos tramos del sistema de irrigación Huiru Catac evidencia el considerable grado de resistencia ante los pasados e inminentes desastres naturales y telúricos de la zona.

2. Los canales que integran el sistema hidráulico fueron construidos, en sus diferentes tramos, según las características físicas y geomorfológicas por donde se diseñó su trazo, empleando los materiales cercanos al área. Dicha acción, permitió reducir tiempos y trabajo en la construcción del mismo.

3. La materialización de un sistema hidráulico a gran escala, como éste, indica la importancia que el riego alcanzó en las comunidades prehispánicas que participaron en su construcción. Dicho proyecto solo se pudo lograr a través de acuerdos entre los grupos culturales asociados al sistema de irrigación que, evidentemente, se beneficiarían del mismo

4. Acerca de su cronología, es probable que dicha obra haya sido construida a fines del Horizonte Medio o inicios del Intermedio Tardío. La evidencia arqueológica parece respaldar esta postura, la cual debería ser profundizada en futuros trabajos.

5. La particularidad de este sistema hidráulico andino reside en su carácter integrador por haber influenciado en tres valles: Jimbe, Macate y Lacramarca. Como lo anotaba Grillo (1988), las características más importantes de las sociedades prehispánicas que practicaron la agricultura mediante sistemas de riego, radica en que estaban basadas en un concepto de gestión de cuencas hidrográficas. Dicho contexto estuvo ligado a la gestión social, económica y cultural con el fin de garantizar la construcción y el mantenimiento de la infraestructura hidráulica. 


\section{BIBLIOGRAFÍA}

Antúnez de Mayolo, S. (1986). El riego en Aija. Allpanchis (N²8, Año XVIII), 47-71.

Antúnez de Mayolo, S. (1986). Hidráulica Costera Prehispánica. Allpanchis (№27, Año XVIII), $11-37$.

Aspillaga, A. (24 de Agosto de 1953). Rocro y Palacio Colcap. El Comercio, pág. 8.

Bastiand, M. (2006). El estilo de la cerámica Casma del Intermedio Tardío. Revista del Instituto de Investigaciones Histórico Sociales, 10(17), 91-119.

Bazán, F. (2011). Asentamientos tardíos del Santo Toribio y del Auquish Urán. En K. Lane, \& M. Luján (Edits.), Arquitectura prehispánica tardía: construcción y poder en los Andes centrales (UCSS ed., págs. 93--118).

Berrocal, M. (2014). Lagunas: Espacios sagrados y sistemas hidráulicos prehispánicos. Alteritas. Revista de estudios socioculturales andino amazónicos (3), 121-148.

Carlier, A. (2008). Le nettoyage rituel des canaux d'irrigation d'une communauté de la cordillère de Lima (province de Canta, Pérou) : une approche ethnohistorique. Bulletin de l'Institut français d'études andines, 37 (2), 351-374.

Carrión, R. (2005 [1955]). El culto al agua en el Antiguo Perú. Lima: Instituto Nacional de Cultura.

Cavero, Y. (2010). Inkapamisan: ushnus y santuario inca en Ayacucho. Ayacucho, Perú.

Contreras, D. (2010). Landscape and Environment: Insights from the Prehispanic Central Andes. Journal of Archaeological Research, 18, 241-288.

Dagget, C. (1983). Casma Incised pottery: an analysis of collections from the Nepeña Valley. Investigations of the Andean Past. Papers from the First Annual Northern Conference on Andean Archaeology an Ethnology (págs. 209-225). Cornell University.

Deeds, E., Kus, J., Moseley, M., Nials, F., Ortloff, C., Pipin, L., . . Pozorski, T. (1978). Un estudio de irrigación prehispánica en Pampa Esperanza, Valle Moche: Metodología y resultados preliminares. En R. Matos (Ed.), III Congreso Peruano. El hombre y la Cultura Andina-Actas y trabajos. Tomo I (págs. 217-238).

Deza, J. (2001). iSe seca la costa? Ideología y riego prehispánico en el norte peruano. Lima: Fondo Editoral Universidad Alas Peruanas.

Deza, J. (2010). El Agua de los Incas (Segunda ed.). Lima, Perú: Fondo Editorial Universidad Alas Peruanas.

Farfán, C. (2002). El simbolismo en torno al agua en la comunidad de Huaros-Canta. Bulletin de l'Institut français d'études andines, 31 (1), 115-142. doi:10.4000/bifea.6967

Farrington, I. (1978). Irrigación prehispánica y establecimientos en la costa norte del Perú. En R. Ravines, Tecnología Andina (págs. 117-128). IEP.

Farrington, I. (1980a). The archaeology of irrigation canals, with special reference to Peru. En World Archaeology, Vol. 11, No. 3, Water Management (págs. 287-305).

Farrington, I. (1980b). Un entendimiento de sistemas de riego prehistórico en Perú. En América Indígena (Vol. XL, págs. 691-712). 
Gambini, W. (1975). Monografía de Cáceres del Perú.

Gambini, W. (1984). Santay Nepeña. Dos valles/Dos culturas.

Garcilaso, I. d. (1959). Comentarios reales de los Incas. Lima: UNMSM.

Gelles, P. (1986). Sociedades Hidráulicas en los Andes: Algunas perspectivas desde Huarochirí. Allpanchis (N²7, Año XVIII), 99-147.

Gelles, P. (2002). Agua y poder en la sierra peruana: la historia y política cultural del riego, rito y desarrollo. Lima: Fondo Editorial Pontificia Universidad Católica.

Gerbrandy, G., \& Hoogendam, P. (1998). Agua y acequias: los derechos al agua y la gestión campesina de riego en los Andes bolivianos. Cochabamba, Bolivia: Plural Editores.

Glowacki, M., \& Malpass, M. (2003). Water, huacas, and ancestor worship: Traces of a sacred Wari landscape. Latin American Antiquity, 14(4), 431-448.

Greslou, F. (1988). Consideraciones sobre el agua en la agricultura andina. En E. Grillo, F. Greslou, J. Osterkamp, B. Coolman, \& M. Bueno, Agua y Agricultura Andina (págs. 29-40). CAME, Proyecto de Teconologías Campesinas.

Gridilla, A. (1937). Ancash y sus Antiguos Corregimientos. Arequipa: La Colmena.

Grillo, E. (1988). Notas sobre el riego en el Perú. En E. Grillo, F. Greslou, J. Oosterkamp, B. Coolman, \& M. Bueno, Agua y Agricultura Andina. Lima: CAME, Proyecto de Teconologías Campesinas.

Herrera, A. (2005). Territory and Identity in the pre-Columbian Andes of Northern Peru. (Tesis de $\mathrm{PhD})$, University of Cambridge, Department of Archaeology.

Hyslop, J. (2016). Asentamientos planificados Inka. Lima: Ediciones Copé.

Kendall, A. (2008). Terrazas, una infraestructura agrícola como contribución. XII Congreso de Historia Agraria. Córdoba.

Kendall, A., \& Rodríguez, A. (2009). Desarrollo y perspectivas de los sistemas de andenería de los andes centrales del Perú. Cuzco, Perú: Institut français d'études andines, Centro de Estudios Regionales Andinos Bartolomé de Las Casas.

Kosok, P. (1965). Life, land and water in Ancient Peru. Long Island University Press, New York.

Lane, K. (2006a). Engineering the Puna: The hydraulics of agro-pastoral communities in a Northcentral Peruvian valley. $\mathrm{PhD}$. Tesis doctoral, University of Cambridge, Archaeology, Cambridge.

Lane, K. (2006b). Through the Looking Glass: Re-Assessing the Role of Agro-Pastoralism in the North-Central Andean Highlands. En World Archaeology (Vol. 38, págs. 493-510).

Lane, K. (2009). Engineered highlands: the social organization of water in the ancient northcentral. En World Archaeology (págs. 169-190).

Lane, K. (2011). Hincapié en los Andes Nor-centrales: la presencia Inca en la Cordillera Negra, Sierra de Ancash. En K. Lane, \& M. Luján (Edits.), Arquitectura prehispánica tardía: construcción y poder en los Andes centrales (págs. 123-170). Universidad Católica Sedes Sapientiae, Fondo Editorial.

Lane, K. (2014). Water Technology in the Andes. En Encyclopaedia of the History of Science, Technology, and Medicine in Non-Western Cultures (págs. 1-24). 
Jesús Maza Poma

Lane, K., \& Grant, J. (2016). A Question of Altitude: Exploring the limits of highland pastoralism in the prehispanic Andes. En The Archaeology of Andean Pastoralism (págs. 139-157). University of New Mexico Press, Albuquerque.

Maza, J. (2016). Informe Técnico Arqueológico. Reconocimiento arqueológico al canal Huiru Catac y sitios arqueológicos periféricos. Trabajo en posesión del autor. Obtenido de:

https://www.academia.edu/31535211/Reconocimiento_arqueol\%C3\%B3gico_al_canal_H uiru_Catac_y_sitios_arqueol\%C3\%B3gicos_perif\%C3\%A9ricos

Maza, J. (7 de Noviembre de 2017). Arqueólogos hallan aldea prehispánica en cuenca alta del río Nepeña. La Industria de Chimbote, pág. 9.

Maza, J. (10 de Abril de 2017). Conozca el canal prehispánico ubicado en el valle de Nepeña. La Industria de Chimbote, pág. 16.

Maza, J. (Enero de 2018). Tzaqanan, ruinas escondidas en las alturas de Jimbe. El Ferrol, Año XII $n^{\circ} 110,20$.

Middendorf, E. (1973). Perú: Observaciones y estudios del país y sus habitantes durante una permanencia de 25 años. Tomo II y III. (E. More, Trad.) Lima: UNMSM.

Mitchell, W. (1976). Irrigation and Community in the Central Peruvian Highlands. American Anthropologist, 78, 25-44.

Mitchell, W. (1981). La ingeniería hidráulica Chimú. En H. Lechtman, \& A. Soldi, La tecnología en el mundo andino (págs. 135-167). México: Universidad Nacional Autónoma de México.

Navarro, J. (2015). Informe Técnico de los trabajos de campo Temporada 2015-PIADCA. Trujillo.

Navarro, J. (2016). Informe Técnico de los trabajos de campo Temporada 2016-PIADCA. Trujillo.

Oré, M. (2005). Agua: bien común y usos privados: riego, estado y conflictos en La Archirana del Inca. Lima, Perú: Fondo Editorial de la Pontificia Universidad Católica del Perú.

Ortloff, C. (1981). La ingeniería hidráulica Chimú. En H. Lechtman, \& A. M. Soldi, La tecnología en el mundo andino (Primera ed., págs. 91-134). México: Universidad Nacional Autónoma de México.

Ortloff, C. (2016). Canals and Aqueducts in the Ancient World. En Encyclopedia of Geoarchaeology (págs. 96-105).

Ortloff, C., \& Moseley, M. (2009). Climate, Agricultural Strategies, and Sustainability in the Precolumbian Andes. Andean Past, 9, 277-304.

Ortloff, C., Feldman, R., \& Moseley, M. (1985). Hydraulic engineering and historical aspects of the Pre-Columbian intravalley canal systems of the Moche Valley, Peru. Journal of Field Archaeology, 12(1), 77-98.

Ortloff, C., Moseley, M., \& Feldman, R. (1982). Hydraulic Engineering Aspects of the Chimu Chicama-Moche Intervalley Canal. American Antiquity, 47 (4), 572-595.

Perales, M., \& Loayza, H. (2011). Nuevas evidencias de infraestructura asociada al sistema hidráulico del complejo arqueológico de Tunanmarca, Jauja. Revista Apuntes de Ciencia E Sociedad, 1(2), 100-110. 
Pérez, I., \& Salvatierra, A. (2012). El canal de agua que abastecía a la ciudad de Wari, Ayacucho: Proceso constructivo y componentes de funcionalidad. (P. van Dalen, \& L. Flores, Edits.) Arqueología y Sociedad (24), 283-300.

Pozorski, T., \& Pozorski, S. (1982). Reassessing the Chicama-Moche Intervalley Canal: Comments on "Hydraulic Engineering Aspects of the Chimu Chicama-Moche Intervalley Canal". American Antiquity, 47 (4), 851-868.

Proulx, D. (1973). Archaeological Investigations in the Nepeña Valley, Perú. Research Report Number 13. University of Massachusetts, Anthropology, Amherst.

Proulx, D. (2007). Un reconocimiento arquelógico del valle de Nepeña, Perú. (J. Miasta Gutiérrez, Trad.) Lima: Seminario de Historia Rural Andina. Universidad Nacional Mayor de San Marcos.

Pulgar Vidal, J. (1998). Las ocho regiones naturales del Perú (Décima ed.). Lima, Perú: Peisa.

Regal, A. (2005). Los trabajos hidráulicos del inca en el Antiguo Perú (Segunda ed.). Lima: Instituto Nacional de Cultura.

Salvatierra, A. (2010). Aproximaciones al estudio hidráulico e hidrológico del canal Wari de Incapa Yarccan en Ayacucho. (Tesis de pregrado), Universidad Nacional San Cristóbal de Huamanga, Huamanga.

Sherbondy, J. (1982). El regadío, los lagos y los mitos de origen. Allpanchis, Vol. XVII(N²0), 3-32.

Sherbondy, J. (1987). Organización hidráulica y poder en el Cuzco. Revista Española de Antropología Americana, 17, 117-153.

Silva, E. (2016). Las industrias líticas tardías alrededor del nevado Huandoy, Ancash, Perú. (Tesis de pregrado), Universidad Nacional Mayor de San Marcos, Lima.

Squier, E. (1974). Un viaje por tierras incaicas. (R. Peña, Trad.) Buenos Aires, Argentina.

Téllez, S., \& Hayashida, F. (2004). Campos de cultivo prehispánicos en la pampa de Chaparrí. Boletín de Arqueología PUCP(8), 373-390.

Tello, J. (1956). Arqueología del Valle de Casma: culturas: Chavín, Santa o Huaylas Yunga y SubChimú. Lima: San Marcos.

Tello, J. (2005). Arqueología del valle de Nepeña: Excavaciones en Cerro Blanco y Punkurí. Lima: Museo de Arqueología y Antropología. Universidad Nacional Mayor de San Marcos.

Tello, J., \& Miranda, P. (1923). Wallallo: Ceremonias gentilicias realizadas en la Región Cisandina del Perú Central. Revista Inca, Vol. I, 474-549.

Thompson, L. G., Mosley-Thompson, E., Bolzan, J. F., \& Koci, K. R. (1985). A 1500-Year Record of Tropical Precipitation in Ice Cores from the Quelccaya Ice Cap, Peru. Science, 229, 971-973.

Valcárcel, L. (1964). Etnohistoria del Perú Antiguo. Lima: Universidad Nacional Mayor de San Mar$\cos$.

Valderrama, R., \& Escalante, C. (1988). Del Tata Mallky a la Mamapacha. Riego, Sociedad y Ritos en los Andes Peruanos. Lima: DESCO. 
Valdez, L., \& Valdez, E. (1998). Inkapyarqan: Un Canal en las Punas de Ayacucho. Boletín del Museo de Arqueología y Antropología de la Universidad Nacional Mayor de San Marcos (1), 4-9.

Van der Zel, H. (1989). Riego en la Sierra. Cuzco, Perú: PRODERM.

Varon Gabai, R. (1993). Estrategias políticas y relaciones conyugales. El comportamiento de incas y españoles en Huaylas en la primera mitad del siglo XVI. Boletín del Instituto Francés de Estudios Andinos(22), 721-737.

Villafana, J. (1986). Sistemas Hidráulicos Incas. Lima: Lluvia Editores.

Vivanco, C. (2015). Obras hidráulicas de etapa prehispánica en Huaccana, Chincheros - Apurímac. Arqueología y Sociedad (30), 315-333.

Wittfogel, K. (1957). Oriental Despotism. A Comparative Study of Total Power. Yale University Press, New Haven.

Wright, K. (2008). Tipon: obra maestra de la ingeniería hidráulica del imperio de los incas (Primera en español ed.). Lima, Lima: Universidad Nacional de Ingeniería.

Zuloaga, M. (2012). La conquista negociada: Guarangas, autoridades locales e imperio en Huaylas, Perú (1532-1610) . Lima: Institut français d'études andines. 